
\title{
25 Research Square \\ Effect of a Structured Checklist on Quality of Intraoperative Change-of-shift Handoffs: A pre-post control study
}

\section{Ebrahim Nasiri}

Mazandaran University of Medical Sciences

Mojgan Lotfi

Tabriz University of Medical Sciences

Seyyed Muhammad Mahdi Mahdavinoor

Mazandaran University of Medical Sciences

Mohammad hossein Rafiee ( $\sim$ Hosein1373333@gmail.com )

Mazandaran University of Medical Sciences https://orcid.org/0000-0002-0134-8645

\section{Research}

Keywords: Patient Safety, Operating Room, Shift Change, Quality of Care

Posted Date: April 16th, 2021

DOI: https://doi.org/10.21203/rs.3.rs-426651/v1

License: @ (i) This work is licensed under a Creative Commons Attribution 4.0 International License. Read Full License

Version of Record: A version of this preprint was published at Patient Safety in Surgery on July 18th, 2021. See the published version at https://doi.org/10.1186/s13037-021-00299-1. 


\section{Abstract}

Objective: Handoff without a structured format is prone to the omission of information and could be a potential risk to patient safety. We sought to determine the effect of a structured checklist on the quality of intraoperative change of shift handoff between scrubs and circulating.

Methods: We conducted a pre-post control intervention study on operating room wards of two teaching hospitals from February to November 2020. This research was conducted in three stages as follows: assessing the current situation (as a group before the intervention), performing the intervention and evaluating the effect of using a checklist on handoff quality after the intervention in two groups: with and without checklist. We examined the quality of handoff between scrub and circular personnel in terms of handoff duration and quality, omission of information as well as changes in personnel satisfaction. Data were analyzed using SPSS software version 26.

Results: A total of 120 handoffs were observed and evaluated. After intervention in the group using the checklist, the percentage of information omission in surgical report was decreased from 19.5 to $12.1 \%$ between scrubs $(P<0.00)$ and from 16.8 to $14.1 \%$ between circulating $(P<0.03)$. Also, in the role of scrub, the mean overall score of handoff process quality was significantly higher after the intervention $(\overline{\mathrm{x}}=7 \pm 1.5)$ than before it $(\overline{\mathrm{x}}=6.5 \pm 0.9)(\mathrm{p}<0.02)$. In the role of circulating, despite the positive effect of overall score checklist, no significant difference was observed $(p<0.08)$. The use of checklist significantly increased the handoff duration between scrubs $(p<0.03)$ and circulating $(p<0.00)$.

Conclusion: Structured checklist has a positive impact on improving the quality of communication between the surgical team, reducing the information omission rate and increasing the satisfaction.

\section{Introduction}

The transfer of essential information and patient care responsibilities from one health care provider to another is a crucial component of communication in health care, which is known as handoff.[1] Effective communication during handoff is among the main priorities of health care. In handoff, accurate transfer of information regarding the status and care plan safeguards the safety and continuity of patient care.[2, 3]

On average, 4.8 hand off transfers is performed per patient in an operating room.[4] Moreover, the surgical team is responsible for patient's safety during surgical care because the patient cannot inform the team in case there is incorrect information, which indicates the importance of attempts to prevent mistakes in the operating room.[5]

Studies have shown that $21-65 \%$ of errors and mistakes of patient care during surgery are related to communication problems during handoff. [6] Communication errors often occur every seven to eight minutes in the operating room. In $90 \%$ of cases, these errors have adverse effects on surgery in multiple 
ways, including delays, surgical errors, waste of resources, team tension, omission of information, or unfavorable events.[7-9]

The time of shift delivery during surgery is among critical mattes in which irreversible errors can occur; given that the operating room staff work according to the shift schedule, it is possible to change the shifts of scrubs and circulars occur when the surgery is prolonged. At the time of delivery, information are transmitted concerning patient's characteristics, medical records and illnesses, as well as equipment considerations (including plate location, time and pressure of the tourniquet, etc.). Besides, information on countable items, location of seizures, samples and drugs on the sterile field and so on should be transferred. Defective transmission of such information can endanger the safety and even the life of patient.[10,11]

In various studies, several factors such as lack of personnel training, absence of standardization, nonexistence of face-to-face communication, passive transfer (without the possibility of interactive discussion), interruptions and time constraints have been mentioned as barriers to successful handoff. [12-14]

For this reason, international organizations and agencies all over the world have stressed the need for standardization of this part of care, so that Joint Commission stated the standardization of communications as a priority of health care organizations in 2012. The World Health Organization (WHO) has also recommended and supported the development of a structured process. Health Research and Quality Agency (AHRQ) also calls for formalization of communication processes, which can help decrease errors at this critical time of patient care process.[15-18]

In our literature review, no study was found to specifically address the impact of standardization of intraoperative change-of-shift handoffs. The descriptive cross-sectional study of Hawthorne et al. examined the application of SBAR standard model (status, background, assessment, recommendation) in communication between surgical team six years after training.[19] The study of Johnson et al. also introduced only the standard SWITCH format for surgical shift delivery but did not intervene to determine its effectiveness.[11]

Therefore, this study was conducted to evaluate the use of a structured checklist during shift delivery at the time of surgery. We hypothesized that the implementation of this intervention would reduce the percentage of information omission and increase the communication quality of handoff process. We also assumed that improving communication between the surgical team could increase their satisfaction.

\section{Methods}

\subsection{Study design:}


This study is was performed as a pre-post control intervention study from February to November 2020 in the operating room wards of Sina and Imam Reza (AS) hospitals affiliated with Tabriz University of Medical Sciences, Iran. We sought to determine the effect of a structured checklist on quality of intraoperative change of shift handoff between scrub and circulating.

At the beginning of the current project, there was no standard program for shift change handoff between circulating and scrubs during surgery. To achieve the objectives of the research, first we reviewed the literature on the Internet by searching for the following keywords: Operation room, handoff, perioperative, handover, shift report, sign out, shift change, information, checklist, and the guidelines and standards related to documentation in the operating room were also investigated. According to reviews, the SWITCH checklist was found for the change of shift handoff during surgery. To complete the checklist and adapt it to the present situation, the SWITCH checklist was revised by reviewing the guidelines provided by AORN and AST associations; subsequently, based on the opinions of faculty members and specialists in the field, final editing was performed and examined for validity and reliability.

This study was performed in three stages as follows. The first stage was to evaluate the current situation in terms of handoff quality before the intervention, the second stage was to perform the intervention by training, introducing a checklist and its application in shift delivery during surgery, and the third stage was to assess the effect of using a checklist on handoff quality after the intervention.

Inclusion criteria in this study were all circulating and scrub personnel with at least one year of experience in the relevant field, and exclusion criteria were people who had previously been trained on how to deliver shifts by a checklist or another shift delivery program or who did not wish to continue the study.

Before the intervention, we observed and evaluated sixty cases of handoff for the initial assessment, which were defined as Group A (no knowledge or use of checklist). After the intervention, sixty handoffs were reviewed as group $B$ (as a control group with knowledge but no use of checklist) and group $C$ (with the use of the checklist attached on operation room wall). For all handoffs in Groups $A$ and $B$, the personnel were instructed to give a handoff as usual. For all handoffs in Group C, the staff were told to handoff the patient using the checklist.

\subsection{Intervention:}

In order to conduct the study, after receiving the license, ethical code and performing the administrative steps, we recruited 40 operating room staff working in the two hospitals under study by explaining the objectives of research for them.

We held a training session in the operating room of both hospitals for 30 minutes on two separate days. Those who were not present in the work shift on that day were trained individually, and all questions of staff were answered and ambiguities resolved. Then, we considered a one-week interval for normalizing the researcher's presence in the ward as a member of the group and eliminating its effect on staff behavior. During this period, the researcher was present in the operating room as a member of the group but collected no data. After one week, the researcher was present in the ward every day before shift 
delivery and evaluated the handoff with the relevant assessment forms. Also, all personnel were unaware of the specific criteria of data collection.

Samples were taken by convenience sampling, which was observed and evaluated proportionally according to the type of surgery and the role of personnel (circulating or scrub), meanwhile, sampling was done when all participating members of the handoff expressed their satisfaction of the study.

\subsection{Data collection tools}

The standard CEX-instrument care delivery assessment tool was used to evaluate the quality of handoff process. $[20,21]$ This tool is rated on a scale of $1-9$, which is used to evaluate the information transfer process in six areas, including environment, organization, communication skills, content, clinical judgment, professionalism and overall delivery competence. The Persian version of "CEX-instrument" was prepared based on the standard translation and equivalence process steps.

To assess the quality of handoff content and the amount of omitted information transfer, the data collection form extracted from 17 items provided by the Association of Surgical Technologists (AST) was used to deliver the standard shift.[10]

Since staff satisfaction is one way to evaluate the results of using a standard method, we used the edited questionnaire of Petrovic study after confirming its validity and reliability. [22] In this questionnaire, the level of satisfaction is measured in the form of 10 questions using a five-point Likert scale, of which a score of 1 means complete disagreement and a score of 5 denotes full agreement.

\subsection{Analysis}

We used SPSS (version 26) statistical software for data analysis. Descriptive indicators were used to determine the mean, standard deviation, and Kolmogorov-Smirnov method was employed to examine the normal distribution of data. In case of normal and abnormal data distribution, t-test and Mann-Whitney test was used, respectively. $P<0.05$ was considered significance level in this study.

\section{Results}

A total of 120 handoffs were observed during intraoperative change-of-shift between circular and scrub members of the surgical team. The number of participants in these handoffs was 40 . The mean and standard deviation of participants' ages were $32.2 \pm 5.6$ years. Other demographic information of personnel is given in Table 1. 
Table 1

Demographic information in the two hospitals surveyed

\begin{tabular}{|c|c|c|c|c|}
\hline \multicolumn{2}{|l|}{ Characteristic } & \multirow{2}{*}{$\begin{array}{l}\text { Hospital-1 }(\mathbf{n}= \\
\text { 22) } \\
\text { 32.8(SD = } \\
7.31)\end{array}$} & \multirow{2}{*}{$\begin{array}{l}\text { Hospital-2(n= } \\
\text { 18) } \\
\begin{array}{l}30.02(\mathrm{SD}= \\
4.96)\end{array}\end{array}$} & \multirow{2}{*}{$\begin{array}{l}\text { P-value } \\
\text { T test: } 0.36\end{array}$} \\
\hline Age (years) & & & & \\
\hline \multirow[t]{2}{*}{ Sex } & Male & 8 & 6 & \multirow{2}{*}{$\begin{array}{l}\text { Chi square: } \\
0.32\end{array}$} \\
\hline & female & 13 & 12 & \\
\hline $\begin{array}{l}\text { Work history } \\
\text { (years) }\end{array}$ & & $10(\mathrm{SD}=6.85)$ & $9.2(\mathrm{SD}=7.22)$ & T test: 0.77 \\
\hline \multirow[t]{2}{*}{ Education level } & \multirow{2}{*}{$\begin{array}{l}\text { Associate degree Bachelor's } \\
\text { degree }\end{array}$} & 4 & 5 & Chi square: \\
\hline & & 17 & 13 & 0.89 \\
\hline \multirow{3}{*}{$\begin{array}{l}\text { Type of } \\
\text { employment }\end{array}$} & Training course & 6 & 5 & Chi square: \\
\hline & Contractual & 0 & 3 & 0.76 \\
\hline & Permanent & 15 & 10 & \\
\hline
\end{tabular}

\section{Duration of Handoff}

Before the intervention, the mean handoff delivery time between circulations and between scrubs was $\overline{\mathrm{X}}=67.7 \pm 19$ and $\overline{\mathrm{x}}=92.7 \pm 39$ seconds, respectively. The use of checklist significantly increased the handoff time between scrubs (two-sample t-test: $p<0.03$ ) and circulations (two-sample t-test: $p<0.00$ ). There was no significant difference between $B$ and $C$ groups (two-sample t-test: $p<0.8$ ). Information about surgeries and the average duration of shift handoff delivery is presented in Table 2. 
Table 2

Duration of handoff in observed surgeries

\begin{tabular}{|c|c|c|c|}
\hline \multirow[t]{2}{*}{ Type of surgery } & \multirow{2}{*}{$\begin{array}{l}\text { Before intervention } \\
\text { Group A } \\
(\mathrm{X} \pm \mathrm{SD})\end{array}$} & \multicolumn{2}{|l|}{ After intervention } \\
\hline & & Group B(without checklist) & Group C(with checklist) \\
\hline Gynecology & $64 \pm 21$ & $89 \pm 11^{*}$ & $84 \pm 8^{*}$ \\
\hline$C$ to $C$ & $110 \pm 24$ & $136 \pm 34^{\star}$ & $153 \pm 27 *$ \\
\hline \multicolumn{4}{|l|}{$S$ to $S$} \\
\hline Neurosurgery & $42 \pm 12$ & $59 \pm 16$ & $74 \pm 9 *$ \\
\hline $\mathrm{C}$ to $\mathrm{C}$ & $114 \pm 21$ & $142 \pm 21^{\star}$ & $151 \pm 28^{\star}$ \\
\hline \multicolumn{4}{|l|}{$S$ to $S$} \\
\hline General & $105 \pm 24$ & $131 \pm 23^{\star}$ & $147 \pm 18^{\star}$ \\
\hline $\mathrm{C}$ to $\mathrm{C}$ & $142 \pm 35$ & $144 \pm 28$ & $160 \pm 43^{\star}$ \\
\hline \multicolumn{4}{|l|}{$S$ to $S$} \\
\hline Orthopedic & $35 \pm 12$ & $34 \pm 16$ & $28 \pm 16$ \\
\hline $\mathrm{C}$ to $\mathrm{C}$ & $45 \pm 13$ & $51 \pm 17$ & $49 \pm 9$ \\
\hline \multicolumn{4}{|l|}{$S$ to $S$} \\
\hline Urology & $62 \pm 9$ & - & - \\
\hline$C$ to $C$ & $54 \pm 14$ & & \\
\hline \multicolumn{4}{|l|}{$S$ to $S$} \\
\hline All surgery & $67 \pm 19$ & $76 \pm 34^{\star}$ & $85 \pm 39 *$ \\
\hline $\mathrm{C}$ to $\mathrm{C}$ & $92 \pm 39$ & $118 \pm 21^{*}$ & $128 \pm 21^{\star}$ \\
\hline \multicolumn{4}{|l|}{$S$ to $S$} \\
\hline C: Circulating nu & e, S: Scrub technician & & \\
\hline * $P<0.05 ;$ signifi & ant difference from & fore intervention & \\
\hline
\end{tabular}

\section{Handoff process quality}

The review results of handoff process quality include six areas: environment, organization, communication skills, content, clinical judgment, and professionalism. The results showed that the overall score of handoff process quality in group $C$ (with checklist) after the intervention in the role of scrub was $\overline{\mathrm{x}}=7 \pm 1.5$, which was significantly higher than before the intervention $\overline{\mathrm{x}}=6.5 \pm 0.9(\mathrm{p}<0.02)$. In 
the role of circulating, despite the positive effect of checklist in all six areas, there was no significant difference in the overall score between before $(\bar{x}=5.9 \pm 1.6)$ and after the intervention $(\bar{x}=6.9 \pm 0.7)(p<$ 0.08). Comparison of the scores of handoff process quality before and after the intervention is presented in Figs. 1. As can be seen from the diagram, the most significant increase in handoff quality after the intervention was in the areas of communication skills, organization and professionalism.

\section{Handoff content quality}

On average, the percentage of information omission related to shift delivery during surgery before the intervention between two circulating subjects was $\bar{x}=17.3 \pm 19.4$, $(\operatorname{Min}=0, \operatorname{Max}=76)$, which was $\bar{x}=18 \pm$ 16.3 (Min = 0, Max $=65$ ) between two scrub subjects. Details of the percentage of information omission in the handoff before and after the intervention is given in Fig. 2.

After the intervention, the percentage of information omission in group $B$ (handoff without checklist) between two circulating individuals was $\bar{x}=16.9 \pm 17$ (Min $=0$, Max $=69)$ and was $\bar{x}=15 \pm 16.6$ between two scrub individuals ( $\mathrm{Min}=0, \mathrm{Max}=58$ ). Statistical analysis showed no significant difference between circulating $(p<0.79, t=0.3, d f=19)$ and scrub handoff $(p<0.1, t=1.6, d f=19)$ in group $B$ with before the intervention.

After intervention in group $C$ (handoff with checklist), the percentage of information omission between two circular individuals was $\bar{x}=14 \pm 16.8(\operatorname{Min}=0, \operatorname{Max}=72)$ and was $\bar{x}=12.1 \pm 14.7(\min =0, \operatorname{Max}=55)$ between two scrub individuals. Statistical analysis showed a significant difference between circulating ( $p$ $<0.03, t=2.2, d f=19)$ and scrubs handoff $(p<0.00, t=3.3, d f=19)$ in group $C$ before the intervention.

After the intervention, there was no significant difference between $B$ and $C$ groups, the percentage of information omission in handoff reports during surgery between the circulations $(p<0.03, t=-2.3, d f=19)$. However, there was a significant difference between scrubs handoff $(p<0.02, t=2.5, d f=19)$.

\section{Staff satisfaction from handoff}

A total of 30 handoff satisfaction survey questionnaires were completed out of 40 personnel participating in this study whose handoff was surveyed. The overall mean percentage of handoff satisfaction increased from $67.5 \%$ before the intervention to $85.5 \%$ after the intervention, which was also statistically significant $(p<0.00, t=3.5, d f=18)$. Table 3 shows the percentage of answers to questions before and after the intervention. 
Table 3

Surgical Team Satisfaction from handoff

\begin{tabular}{|c|c|c|c|c|}
\hline \multirow[b]{2}{*}{ Items } & \multicolumn{2}{|c|}{ pre } & \multicolumn{2}{|c|}{ post } \\
\hline & $\mathbf{n}$ & $\begin{array}{l}\text { agree and } \\
\text { strongly } \\
\text { agree\% }\end{array}$ & $\mathbf{n}$ & $\begin{array}{l}\text { agree } \\
\text { and } \\
\text { strongly } \\
\text { agree\% }\end{array}$ \\
\hline 1. I was satisfied with the handoff for this patient & 20 & $65 \%$ & 28 & $93 \%$ \\
\hline 2. I could hear all of the report & 24 & $85 \%$ & 28 & $93 \%$ \\
\hline 3. I received information about potential problems that could & 26 & $85 \%$ & 26 & $86 \%$ \\
\hline 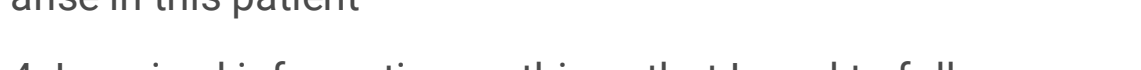 & 22 & $75 \%$ & 20 & $66 \%$ \\
\hline & 20 & $65 \%$ & 28 & $93 \%$ \\
\hline . & 27 & $90 \%$ & 28 & $93 \%$ \\
\hline $\begin{array}{l}\text { 6. I was clear as to when the handoff actually started and } \\
\text { ended }\end{array}$ & 17 & $55 \%$ & 24 & $80 \%$ \\
\hline 7. Shift delivery reports allow me to prioritize my tasks. & 20 & $65 \%$ & 19 & $63 \%$ \\
\hline 8. Immediately after nurse-to-nurse shift report, I am able to & 12 & $40 \%$ & 28 & $93 \%$ \\
\hline 9. The length of report is an effective use of my time & 15 & $50 \%$ & 28 & $93 \%$ \\
\hline $\begin{array}{l}\text { 10. Mistakes in patient care and equipment rarely occur in the } \\
\text { current shift delivery process }\end{array}$ & & & & \\
\hline Total mean & & $67.5 \%$ & & $85.5 \%$ \\
\hline
\end{tabular}

\section{Discussion}

We found that having a checklist in the operating room improves the quality of intraoperative change of shift handoff for scrubs and circulating, although the increasing quality of handoff process was only significant for scrubs. Also, the presence of a checklist in the operating room significantly reduces the omission percentage of information in the shift report during surgery in both circulations and scrubs compared to before the intervention.

After performing the intervention and introducing the contents of checklist and the items to be transferred during the shift delivery at the time of surgery, an increase in handoff duration was seen in both $B$ and $C$ groups (with and without checklists) with the improvement of data transfer status.. The difference between this increases of time in the checklist group before the intervention was 35.3 seconds among scrubs and 17.3 seconds among circulations. Researchers in similar studies have reported different perceptions of increasing or decreasing handoff duration after intervention and introduction of a 
checklist.[2, 23-25] For example, in the study of Salzwedel et al., the increase in handoff time, which was less than 1 minute in their study, was considered to be short-lived, and this slight increase in time was compared to the improvement in the status of information transfer as well as quality of positive patient care.[2] In contrast, in the study of Catchpole et al., a decrease was observed in the handoff duration by intervening and introducing a checklist, citing the structuring of handoff and defining responsibilities.[24]

Increasing handoff duration in this study may not be economically viable at first glance; however, this slight increase over time can be ignored because of the positive aspects of using a checklist to reduce the amount of omitted information that improves the quality of handoff process and ultimately increases the quality of patient care.

The quality of handoff process in this study was evaluated in two aspects: environment (noise and interruptions created) and behavior (organization, communication skills, clinical judgment and professionalism). According to the results of the environmental aspect, no change in the improvement of situation was observed after the intervention. In other similar studies, for example, in the Lo study concerning the handoff delivery of medical attending, or in the study of Joy investigating the patient handoff between cardiac surgery department and ICU, improvement in the environment and interruptions during the handoff after the application of the checklist have been reported.[26, 27]

However, the operating room environment is full of sound generating sources (sound of electrical equipment, air conditioning system, moving devices and tools, etc.).[28,29] these sounds can have many adverse effects on the correct transmission of information. On the other hand, the circulating and scrub roles during surgery are such that multiple interruptions during handoff are inevitable. Therefore, in this study, after the intervention, we did not observe any significant change in the environment of handoff process. However, behavioral intervention in the two areas of handoff organization and communication skills showed better results, which was made possible due to the existence of a checklist. In other words, the existence of a checklist enabled the surgical team to resume the process of transferring information from the part that had been stopped despite numerous interruptions. On the other hand, the checklist improves communication skills by approaching the deliverer and recipient to each other. This occurred during the handoff, and eventually reduced the lost information of handoff reports despite lack of change in the scope of environment after the intervention.

Our findings support the study hypothesis that we can increase the quality of handoff content during surgery by introducing a relatively structured and regular method.

Hanley cites three potential reasons for handoff errors: interruptions during hand-off, lack of standard format, and unreliability of the sender and receiver of the information to be transmitted.[30] In this study, by performing the intervention despite the inability to control interruptions during handoff via introducing the standard format and teaching the information to be transferred during shift delivery, we observed a reduction in information omission percentage as well as improved quality of handoff content in both circular and scrub roles. 
The use of a standard model for handoff in similar studies has also improved the information transfer. In the study of Ding et al., the patient handoff between neurological intensive care unit to neurological department after the intervention showed a reduction in handoff errors from 18.8-5.7\%.[31]

In the study of Craig et al., the percentage information omission was reduced from $36.8 \%$ before the intervention to $15.7 \%$ after it through introducing the standard format for handoff among cardiology and ICU staff (28). In Mitchelle's study on the same statistical population, the amount of information lost after the intervention was reduced from 26 to $18 \%$ (29). In the Negpal's study, the amount of information lost after using the standard checklist was reduced from 9 to 3.[3]

Participants' satisfaction is another important element in evaluating the success of an intervention. In the present study, handoff satisfaction increased from 67.5-85.5\% using the checklist, which was consistent with previous studies that have successfully implemented a standard handoff process. In the study of Petrovic et al., the satisfaction of recovery nurses with handoff increased from $73.8-92 \%$ after using the checklist for patient transfer.[22] In a study by Johnson et al., nurses' satisfaction with patient's handoff after the introduction of checklist increased from a total score of 21.7 to 24.[32] In the study of Kazemi et al., which was conducted with the aim of evaluating the effect of delivery of nurses' shifts in the patient's bedside with patient's participation, total satisfaction score increased from 81.6 to 93.[33]

\section{Limitations}

One of the limitations of our study was the evaluation of shift-change handoff during surgery with the presence of a researcher in the operating room, which could cause Hawthorne effect and influence the results. However, this effect was limited because the assessor did not communicate with the surgical team during handoff. Also, the assessor was present in both periods before and after the intervention. On the other hand, the researcher was not a member of the operating room staff and had no control over them. Nevertheless, the presence of an assessor was necessary to evaluate the handoff in the operating room, unless a camera was used in subsequent studies to assess handoff to reduce the effect. Another limitation was the COVID-19 pandemic during the study, which could affect the research process and was beyond the researcher's control, although this effect was the same in both $B$ and $C$ groups.

\section{Conclusion}

This study showed that the use of a standard format among the surgical team in health centers has a positive effect on increasing quality of communication process and reducing the omission percentage of information as well as increasing the satisfaction of surgical team during shift delivery at the time of surgery. Therefore, we recommend standardized tools in critical situations such as shift change handoff during surgery after receiving the necessary training. We also suggest that in future studies, the effect of intervention and the use of a standard checklist on the outcome of possible injuries to the patient should be investigated. 


\section{Declarations}

\section{Acknowledgments}

We would like to thank the Clinical Research Development Unit of Sina and Emam Reza Educational, Research and Treatment Centers, Tabriz University of Medical Sciences, Tabriz, Iran. For their assistances in this research.

\section{Authors' Contribution}

MHR and EN did overall supervision, material provision, study conception. MHR and SMMM did data accumulation. EN did statistical analysis, data provision. MHR did data provision, manuscript preparation. ML did manuscript preparation, final edit, study conception.

\section{Funding/Support}

No funding was obtained from any organization.

\section{Availability of data and materials}

The datasets used and/or analyzed during the current study are available from the corresponding author on reasonable request.

\section{Ethics approval and consent to participate}

Ethical clearance and approval were obtained from the ethical review board of the Mazandaran University of Medical Sciences, Iran.

Approval ID: IR.MAZUMS.REC.1398.1224

\section{Declaration of competing interests}

No, there are no competing interests for any author.

\section{References}

1. Friesen, M.A., S.V. White, and J.F. Byers, Advances in Patient Safety Handoffs: Implications for Nurses, in Patient Safety and Quality: An Evidence-Based Handbook for Nurses, R.G. Hughes, Editor. 2008, Agency for Healthcare Research and Quality (US): Rockville (MD).

2. Salzwedel, C., et al., The effect of a checklist on the quality of post-anaesthesia patient handover: a randomized controlled trial. International journal for quality in health care, 2013. 25(2): p. 176-181.

3. Nagpal, K., et al., Improving postoperative handover: a prospective observational study. The American Journal of Surgery, 2013. 206(4): p. 494-501. 
4. Christian, C.K., et al., A prospective study of patient safety in the operating room. Surgery, 2006. 139(2): p. 159-73.

5. Chard, R. and M.A.J.A.j. Makary, Transfer-of-care communication: nursing best practices. 2015. 102(4): p. 329-342.

6. Haller, G., T. Laroche, and F. Clergue. Évènements indésirables et problèmes de communication en périopératoire. in Annales françaises d'anesthésie et de réanimation. 2011. Elsevier.

7. Hu, Y.Y., et al., Deconstructing intraoperative communication failures. J Surg Res, 2012. 177(1): p. 3742.

8. Lingard, L., et al., Communication failures in the operating room: an observational classification of recurrent types and effects. BMJ Quality \& Safety, 2004. 13(5): p. 330-334.

9. Etherington, N., et al., Interprofessional communication in the operating room: a narrative review to advance research and practice. Canadian Journal of Anesthesia/Journal canadien d'anesthésie, 2019. 66(10): p. 1251-1260.

10. in Association of Surgical Technologist. Guidelines for Best Practices for Transfer of Patient Care DuringIntraoperative Case Management by the Surgical Technologist. Revised February 2015. http://www.ast.org/uploadedFiles/Main_Site/Content/About_Us/RSOP_Transfer_of_Care_11.21.pdf. Accessed April 2017..

11. Johnson, F., et al., SWITCH for safety: perioperative hand-off tools. AORN journal, 2013. 98(5): p. 494507.

12. Khan, A., et al., Barriers in Handoffs among Nurses in Public Sector Tertiary Care Hospital of Peshawar, Pakistan.

13. Fitzpatrick, J., Barriers to Quality Communication Between Interdepartmental Nurses During Patient Handoff and Their Elimination: Integrative Literature Review Proposal. 2019.

14. Monteiro, C., A.F.M. Avelar, and M.d.L.G. Pedreira, Interruptions of nurses' activities and patient safety: an integrative literature review. Revista latino-americana de enfermagem, 2015. 23(1): p. 169179.

15. Haig, K.M., S. Sutton, and J. Whittington, SBAR: a shared mental model for improving communication between clinicians. Jt Comm J Qual Patient Saf, 2006. 32(3): p. 167-75.

16. Organizations, J.C.o.A.o.H., National patient safety goals. Critical Access Hospital and Hospital National Patient Safety Goals [Internet]. 2006.

17. Randmaa, M., et al., SBAR improves communication and safety climate and decreases incident reports due to communication errors in an anaesthetic clinic: a prospective intervention study. BMJ Open, 2014. 4(1): p. e004268.

18. Dumpson, D., Revision and Execution of a Certified Registered Nurse Anesthetist-Directed Implementation of a Standardized Communication Tool in an Outpatient Surgery Center. 2020, Wilmington University (Delaware). 
19. Hunter, H., et al., Assessing SBAR during intraoperative handoff. Perioperative Care and Operating Room Management, 2017. 6: p. 7-10.

20. Smeulers, M., et al., Safe and effective nursing shift handover with NURSEPASS: An interrupted time series. Applied Nursing Research, 2016. 32: p. 199-205.

21. Horwitz, L.I., et al., Validation of a handoff assessment tool: the Handoff CEX. Journal of clinical nursing, 2013. 22(9-10): p. 1477-1486.

22. Petrovic, M.A., et al., The perioperative handoff protocol: evaluating impacts on handoff defects and provider satisfaction in adult perianesthesia care units. Journal of clinical anesthesia, 2015. 27(2): p. 111-119.

23. Karakaya, A., et al., Implementation of a structured information transfer checklist improves postoperative data transfer after congenital cardiac surgery. European Journal of Anaesthesiology (EJA), 2013. 30(12): p. 764-769.

24. Catchpole, K.R., et al., Patient handover from surgery to intensive care: using Formula 1 pit-stop and aviation models to improve safety and quality. 2007. 17(5): p. 470-478.

25. Zavalkoff, S.R., et al., Handover after pediatric heart surgery: a simple tool improves information exchange. 2011. 12(3): p. 309-313.

26. Lo, H.-y., et al., A QI initiative: implementing a patient handoff checklist for pediatric hospitalist attendings. 2016. 5(1).

27. Joy, B.F., et al., Standardized multidisciplinary protocol improves handover of cardiac surgery patients to the intensive care unit*. Pediatric Critical Care Medicine, 2011. 12(3): p. 304-308.

28. Tsiou, C., G. Efthymiatos, and T.J.T.J.o.t.A.S.o.A. Katostaras, Noise in the operating rooms of Greek hospitals. 2008. 123(2): p. 757-765.

29. Keller, S., et al., Noise peaks influence communication in the operating room. An observational study. 2016. 59(12): p. 1541-1552.

30. Hanley-Gumbs, J., Handoff Communication Among Senior Nursing Students: A Phenomenological Study. 2019.

31. Ding, L., T.-T. Lu, and T.-T. Zou, Application of the SBAR communication technique in patient hand-off from the neurosurgery intensive care unit to neurosurgical units. Chinese Journal of Nursing, 2012. 47(7): p. 627-629.

32. Johnson, M., P. Sanchez, and C.J.J.o.c.n. Zheng, The impact of an integrated nursing handover system on nurses' satisfaction and work practices. 2016. 25(1-2): p. 257-268.

33. Kazemi, M., et al., The Effect Of Delivery Nursing Shift At Bedside With Patient's Partnership On Patients' Satisfaction And Nurses'Satisfaction, Clinical Trial, Quasi-Experimental Study. Journal of Nursing and Midwifery Urmia University of Medical Sciences, 2016. 14(5): p. 426-436.

\section{Figures}




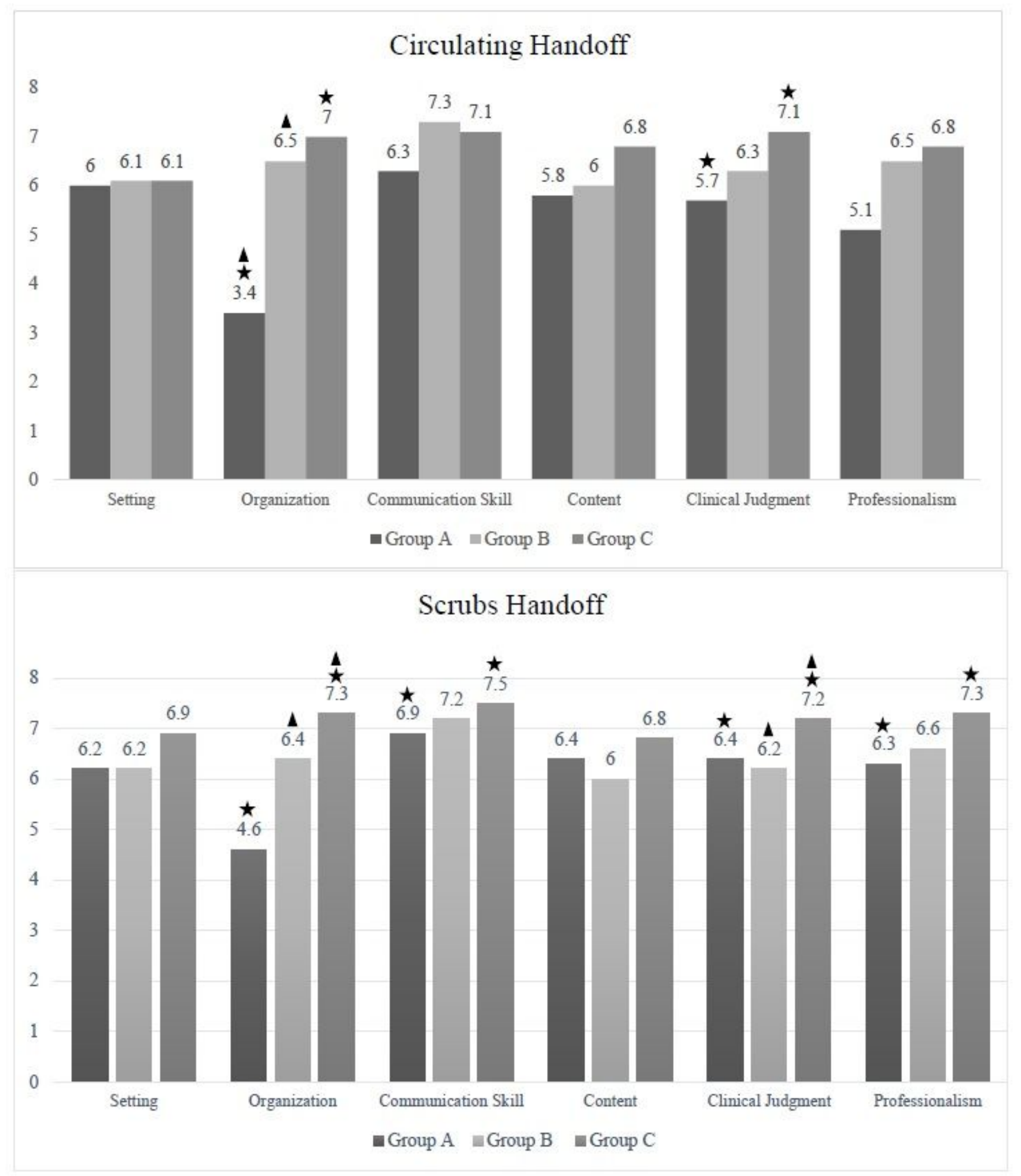

Figure 1

Comparison of the scores of handoff process quality before and after the intervention 
1. Confirm the correct patient, type of surgery and anesthesia

2. Problems occurred for the patient during surgery

3. Patient-specific concerns (allergies, etc.)

4. Surgical stage (early-mid-late)

5. Patient position and potential risks

6. Surgical devices used (toumiquet, etc.)

7. Drugs in the sterile field (type and amount)

8 . Wound washing fluids (type and amount)

9. Confirm if an indwelling catheter is present

10. Position of tools and sets
11. Delivery of important and expensive tools

12. Required items (implants, etc)

13. Tools that need to be prepared for use for the next surgery

14. Tissue and non-tissue samples (name - source.)

15. Grafts(location - type - source)

16. Communicate if waiting on results of frozen section from pathology;

17. sponge on sterile field, off the sterile field and in body cavities

18. Number of sharp items

19. The number, location, type(s), and size(s) of ties

20. Number of instruments
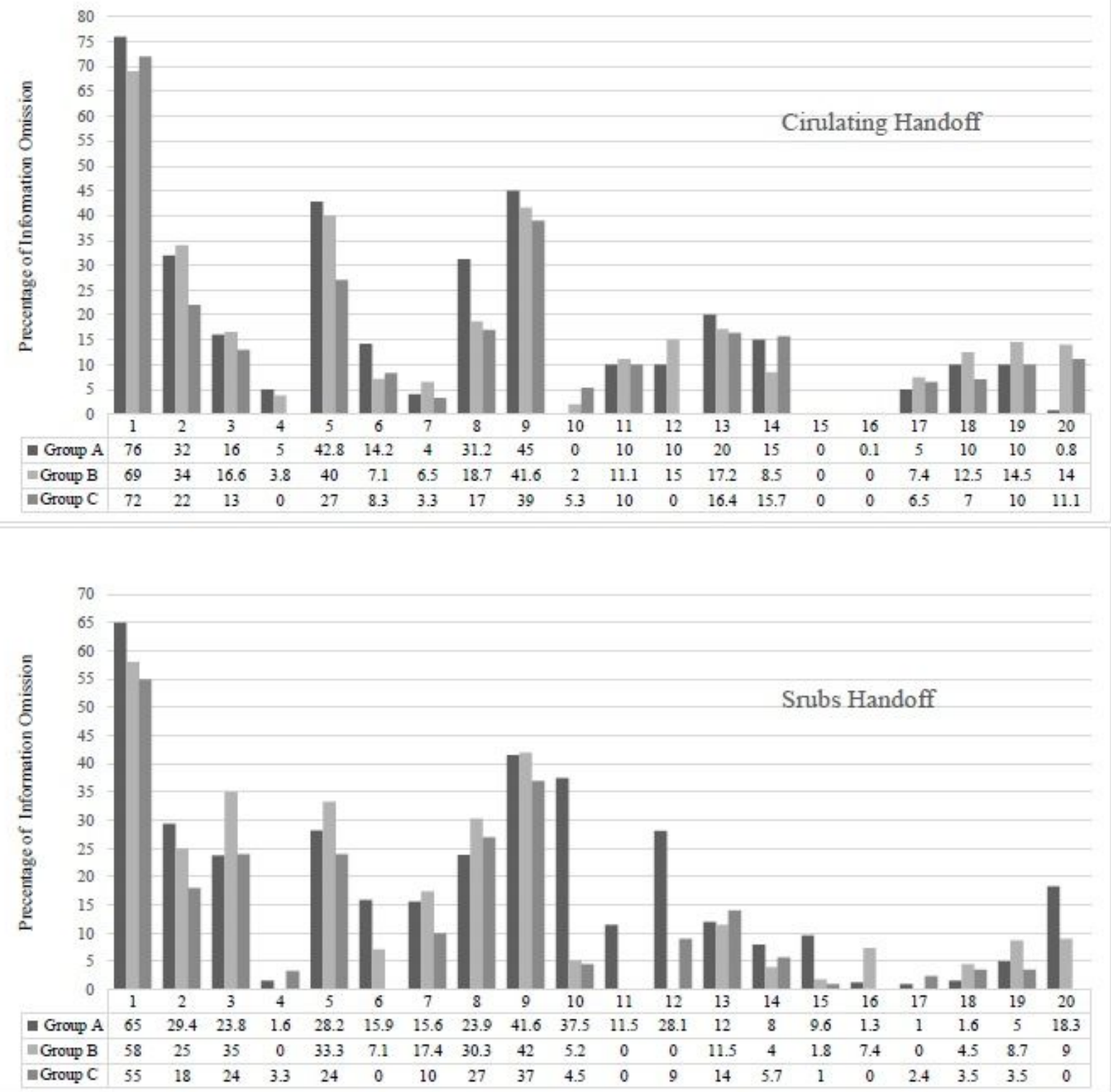

Figure 2

Details of the percentage of information omission in the handoff before and after the intervention 